Case XIr it fell 6 per cent., there being no apparent reason for this as the arsenic agreed well. Nor were the corpuscles affected, except in Gase XIII, where a rise apparently took place at first, but was followed by a fall. Whether this was a real change or simply due to the admitted inaccuracy of the method of counting corpuscles, I am unable to say. In no case did arsenic improve the irregularities in size and contour of the red blond corpuscles. My own opinion is that it exerts no direct influence on the blood in chlorosis.

Whether it has an indirect value in chlorosis when given in combination with iron is very diffi!ult to say. I have several times attempted to compare the relative rapidity with which cases treated with iron alone and iron plus arsenic recover, but it is impossible to do so satisfactorily, for the simple reason that apparently similar cases vary much in the time taken for recovery under the same treatment. In so far as it acts as a gastro-intestinal tonic, arsenic may improve appetite and digestion, and thus indirectly assist in the cure; but if it irritates and lessens appetite it will exert a contrary effect. In fact, certain writers state expressly that they never give it along with iron in chlorosis, because it is apt to disturb digestion. I myself have seen this in several cases, which did much better when arsenic was omitted from the prescription. However, it usually agrees well enough when given in small doses.

The only other point which occurs to me in this connection is one largely, if not purely, theoretical. Arsenic is credited with lessening tissue metabolism, and thus diminishing the amount of oxygen required in the body. In chlorosis the breathlessness is due partly to the lessened oxygen-carrying capacity of the red corpuscles. Arsenic, by diminishing the demand of the tissues for oxygen, may decrease the breathlessness of the patient and thus add to her comfort. The view, however, which 1 wish to emphasise here is that arsenic, if it act beneficially at all in chlorosis, does not do so by any direct effect in increasing the number of the red blood corpuscles or the quantity of hæmoglobin contained in them. [To be continued.

\section{A CASE OF SYMPHYSIOTOMY.}

BY W. J. SMYLY, M.D. Master of the Rotunda Hospital, Dublin.

As the case which I now report is the first in which delivery by division of the symphysis pubis has been successfully carried out in the United Kingdom, I think that it should he recorded. The only occasion npon which it was previously had recourse to was in 1782 , when Mr. Welchman, of Knighton in Warwickshire, delivered a woman of a putrid fœtus in this way. Why he should have selected this method in preference to craniotomy is difficult to understand. The woman's death was not due to the operation, yet the result has certainly deterred others from having recourse to it.

In France, where the operation originated in 1768 , one suc. cessful case was greeted with enthusiasm, and was characterised as the result of inspiration. The Faculté de Médecine voted medals to MM. Sigault and Le Roi, and procured a pension for the former and his patient.

Sigault performed five operations with the loss of one mother and some of the children, by no means a bad record considering the general results of ohstetric operations in maternity hospitals at that time. Its employment by others in unsuitable cases, however, soon brought the proceeding into disrepute, and it sank almost into ohlivion. Its modern revival is due to Professor Morisani, of Naples, but its adoption by Professor Auvard, by Leopold and by Harris, of Philarelphia, have rendered it popular in France, Germany, and the United States of America, and their writings contain all that is at present known of this subject; I need not, therefore, repeat what they have written, but shall simply give an account of my own case.

The patient, Mrs. M., aged 43, was somewhat below the middle height, but without obvious deformity or sign of rickets. She had suffered for the past eight years from chronic articular rheumatism, which had latterly almost com pletely confined her to bed. Her first eight pregnancies had terminated naturally, but the ninth labour was difficult and very protracted. Her usual medical attendant-a practitioner of considerable skill and experience-having failed to deliver her with forceps, sent her into the Rotunda Hospital, where a dead child was extracted.

Upwards of three years after she again became pregnant, and was admitted into the Rotunda on November $19 \mathrm{th}, 1892$, labour having already commenced. On examination the abdomen was found to be pendulous, and the recti muscles widely separated. The uterus hung over to the left side, and the child presented obliquely in the second position, with its head in the right iliac fussa; the os uteri was about the size of a shilling, and the membranes were intact. The sacral promontory could be easily reached by the finger, and the true conjugate of the brim, measured with Skutech's pelvimeter was $7 \frac{1}{2}$ centimetres, or about 3 inches. The presentation having been corrected, and a hinder applied, the patient was directed to lie as much as possit.le on her right side. The labour pains were short and inefficient, and continued so throughout, in spite of hot douches. On November 21st the membranes ruptured, but little progress was made; at night morphine was administered hypodermically, and she had some sleep. During the two following days the os continued slowly to dilate, but the head did not enter the brim of the pelvis. On the evening of November 23rd, the fifth day of labour, the funis prolapsed, and meconium began to come away. The contraction ring could be easily felt a hand's hreadth above the pubes, so that version was impracticable The head was freely movable above the brim, with the sagittal suture in the transverse diameter. Forceps were applied, but grasped the head so unfavourably that I abandoned the attempt to deliver by their means, and determined to resort to symphysiotomy.

The patient was placed in the lithotomy position with the buttocks over the end of the couch and two assistants held her legs on either side. The mons veneris was shaved and as well as the valva and vagina, carefully asepticised. The soft parts were divided with a scalpel in the usual manner, and the first finger of the left hand passed down behind the symphysis, along which a probe-pointed bistoury was guided. The edge of the knife had scarcely touched the cartilage when the bones sprang apart, tearing the soft parts beneath, including the urethra. The child was immediately and without any difficulty expressed by my assistant, and, though deeply asphyxiated, was resuscitated, and is now alive and well. It weighed $7 \frac{1}{2}$ lhs. and measured 20 inches in length. A tolerably brisk hæmorrhage followed the rupture of the soft parts, but was easily controlled by securing a few vessels. The urethra was restored by a catgut suture; the ends of the bones approximated; a few silk sutures closed the wound, which was dressed in the usual manner. A tirm bandage was applied around the hips, and the patient put to bed.

Convalescence was delayed by the formation of a bedsore but she ultimately made a good recovery. The urethra did not completely heal, and there was incontinence of urine, but I was fortunate in being able to cure this by a subsequent operation. Excepting the rheumatic affection already alluded to she went home in perfect health.

From the results of this op+ration in the 54 cases recorded in Dr. Harris's interesting pamphlet, it appears certain that it will take a permanent position amonget our methods of treating labour complicated by pelvic deformity. It has the double advantage of being easy of performance and successfal in its results. If my case be added to those tabulated by Dr. Harris, there were, up to the end of last year, 55 cases with only 1 maternal and 5 fotal deaths.

THE new Biological Station on the Island of Heligoland is now in working order under the direction of Professor Heincke.

Presentation.-Dr. Partridge, of Stroud, has been presented with a silver table gong, sugar basin, and sifter by the members of his ambulance class as a recognition of his services as lecturer.

MEDiCAL Magretrate.- On the recommendation of the Duke of Westminster, the Lord Lieutenant of the County, the Lord Chancellor has appointed Dr. Ralph Gooding, F.I.S., of Blackheath, a Justice of the Peace for the County of London. 